Note

\title{
Decrease in Ovomucoid Antigenicity in the Processes of Breadmaking Supplemented with Egg White
}

\author{
Yasuko KATO, ${ }^{1}$ Hiroko WATANABE ${ }^{1}$ and Tsukasa MATSUdA ${ }^{2}$ \\ ${ }^{1}$ Department of Clinical Nutrition, Medical Professions, Kawasaki University of Medical Welfare, 288 Matsushima, Kurashiki-City, \\ Okayama 701-01, Japan \\ ${ }^{2}$ Department of Applied Biological Sciences, School of Agricultural Sciences, Nagoya University, Chikusa-ku, Nagoya 464-01, Japan
}

Received March 28, 1997; Accepted July 14, 1997

\begin{abstract}
The anitigenic activity of ovomucoid (OM) remaining in bread samples containing egg white was analyzed at several stages of bread making; dough preparation, kneading, fermentation and baking. Change in OM antigenicity at each stage was examined using competitive ELISA with rabbit anti-OM serum. OM antigenicity was remarkably reduced by baking but not by kneading and fermentation. The antigenicity completely disappeared in the breads baked at $150^{\circ} \mathrm{C}$ for $4 \mathrm{~min}$ or more, even though it substantially remained when egg white was heated alone under the same condition. OM in the baked bread samples was solubilized with SDS/2-ME-containing solution but not with the solution containing SDS alone, suggesting that baking with wheat flour induced irreversible denaturation of $\mathrm{OM}$ with a disulfide exchange reaction leading to the loss of its antigenic activity.
\end{abstract}

Keywords: antigenicity, ovomucoid, dough, breadmaking, egg white, wheat flour

Chicken egg is an important food from the standpoints of nutritional value and functional properties and is used in many egg dishes and as an ingredient in many processed foods, such as bread and cookies. Eggs are added to bread for improvement of the water-retention, taste and texture of breads, especially in sweet breads.

Ovomucoid (OM) is a major allergenic protein in chicken egg white (Langeland, 1982a, b; Hoffman, 1983) and is known as a highly heat-stable protein with three well-separated domains crosslinked by three intradomain disulfide bonds. Each domain retains most of the antigenic activity of the parent molecule even after enzymatic or chemical cleavage. The ability to induce mouse IgE and immunoglobulin $G$ (IgG) responses is greatly reduced by proteolytic degradation in each domain. Heat denaturation markedly reduces both the antigenic and the immunogenic activities of OM (Matsuda et al. 1985b). Although heat-induced denaturation of OM is highly reversible under particular conditions (Matsuda et al., 1981), prolonged heating such as boiling for an hour or more induces irreversible denaturation of OM, resulting in the loss of antigenicity (Matsuda et al, 1982). Bleumink and Young (1969) reported that OM prepared from boiled eggs still caused a skin reaction in allergic patients. Egg white proteins retain their antigenicity even after heating $\left(100^{\circ} \mathrm{C}\right.$ for $20 \mathrm{~min}$ ) and the major antigenic component was found to be OM (Gu et al., 1986).

Many food allergens identified in water- and salt-soluble fractions are relatively low molecular weight proteins or glycoproteins and they are often resistant to heat denaturation and proteolytic digestion (Matsuda \& Nakamura, 1993). Like some other allergenic proteins, OM allergenic activity was associated with the heat stability of OM antigenic activity
(Matsuda et al., 1982).

The present study was done to determine how the antigenicity of $\mathrm{OM}$ changes during the breadmaking process including kneading, fermentation and baking. We found that OM antigenicity was markedly decreased by breadmaking processes.

\section{Materials and Methods}

Bread ingredients and preparation of bread The flour used was commercially milled strong bread flour with a $12.8 \%$ protein content and $0.43 \%$ ash content, provided by Nisshin Mills Co., Ltd. (Tokyo). Instant dried yeast (Oriental Yeast Co., Ltd., Tokyo), sugar (Nisshin Sugar Manufacturing Co., Ltd., Tokyo) and salt (Japan Tobacco Ind., Tokyo) were the other ingredients. White Leghorn eggs were used for preparing the bread.

The mixed baking ingredients were kneaded by the straight dough method using a kneader (Taisho Denki Co., Ltd., Kusatsu) at $450 \mathrm{rpm}$. The dough was fermented for $150 \mathrm{~min}$ in a humidifier (Yamato Scientific Co., Ltd., Tokyo, Model IG-43 H.M.) maintained at $30^{\circ} \mathrm{C}$ and $75 \% \mathrm{RH}$ (relative humidity), then punched and divided into small pieces. The dough was immediately subjected to a second fermentation with the chamber maintained at $38^{\circ} \mathrm{C}$ and $85 \% \mathrm{RH}$, until the volume of the dough rose to 2.5 times the original volume. The dough was then baked at $180^{\circ} \mathrm{C}$.

Extraction of soluble proteins Two hundred milligrams of samples (dough and bread) were suspended in $1 \mathrm{ml}$ of PBS (phosphate-buffered saline, pH 7.4), 4\% Sodium dodecyl sulfate (SDS), or 4\% SDS+2-mercaptoethanol (2$\mathrm{ME}$ ) and mixed with a vortex mixer for $1 \mathrm{~min}$ at the maximum speed (Vortex Genie). The suspensions were kept 
overnight at $4^{\circ} \mathrm{C}$ and centrifuged at $16000 \times g$ for $20 \mathrm{~min}$ to remove insoluble proteins. The SDS and SDS/2-ME soluble fractions were used for the analyses directly. One milliliter of the PBS-soluble fraction was freeze-dried and dissolved in 200 $\mu 1$ of distilled water (sample solutions were concentrated 5 times). The solutions were used as soluble protein fractions for the analyses as discussed below.

Polyacrylamide gel electrophoresis and immunoblotting First, the proteins were separated by SDS-gel electrophoresis using $12.5 \%$ acrylamide gels according to the method of Laemmli (1970). One sheet of the gel was stained with Coomassie Brilliant Blue (CBB) R-250, and another gel was used for immunoblotting. The proteins separated by the electrophoresis were transferred electrophoretically onto a nitrocellulose sheet $(0.45 \mu \mathrm{m}$, Advantec Toyo, Tokyo $)$ by the method of Towbin et al. (1979). The nitrocellulose sheet was incubated overnight at $4^{\circ} \mathrm{C}$ in $3 \%$ bovine serum albumin (BSA) in TBS (tris-buffered saline, $\mathrm{pH} 7.5$ ) containing $0.02 \%$ Tween-20 (TBST). After it was washed with TBST, the sheet was incubated at $37^{\circ} \mathrm{C}$ for $2 \mathrm{~h}$ in $5 \mathrm{ml}$ of $1 \%$ BSA containing $5 \mu \mathrm{l}$ of the specific antiserum for OM. The antiserum to OM was prepared as described previously (Matsuda et al., 1982). After it was washed with TBST, the sheet was incubated at $37^{\circ} \mathrm{C}$ for $1 \mathrm{~h}$ in peroxidase-coupling goat anti-mouse immunoglobulin $\mathrm{G}$ (Cappel) appropriately diluted with $1 \%$ BSA/TBST. After washing with TBST, the protein bands with reactivity to the specific antiserum were activity-stained for peroxidase using 4-chloro-1-naphthol (Bio Rad).

ELISA competitive inhibition The antigenic activity of $\mathrm{OM}$ in PBS soluble samples was measured by the competitive inhibition analyses of ELISA (Engvall \& Perlmann, 1971) using rabbit antiserum to OM. Flat-bottomed microtiter plates were coated with OM solution $(1 \mu \mathrm{g} / \mathrm{ml})$. Seventy-five microliters of competitors, serially diluted PBS-soluble fractions extracted from samples, were mixed with the same volume of antibody solution and added to the wells. The rabbit anti-OM serum which reacted with the plate-bound OM was determined using a peroxidase-conjugated goat anti-rabbit IgG antibody (DAKO A/S), as described previously (Matsuda et al., 1982).

\section{Results and Discussion}

Change in the antigenicity of $O M$ in the process of baking bread Dough was prepared by adding 16.7\% egg white to wheat flour, and the PBS-soluble fractions were obtained during the kneading, fermentation and baking stages. The mixed materials were kneaded from 0 to $80 \mathrm{~min}$ with a kneader. Zero kneading time was defined as the point at which all materials were well-mixed. The proteins in the PBS-soluble fractions from the dough were analyzed with SDS-PAGE and immunoblotting (Fig. 1). Many kinds of proteins were observed in the soluble fraction from the dough kneaded for $80 \mathrm{~min}$ on the CBB stained gels. On the other hand, only weak bands were observed in the soluble fractions obtained from bread baked at $180^{\circ} \mathrm{C}$ for $10 \mathrm{~min}$. The antigenicity of $\mathrm{OM}$ remaining in the soluble fractions was analyzed by immunoblotting using the anti-OM antibody. Clearly, many stained bands were obtained in the dough kneaded for $80 \mathrm{~min}$. Not only monomeric OM but also smaller bands were distinctly immunoblotted. The smaller bands might be the fragments of OM hydrolyzed by the protease in wheat flour and/or yeast. Kneading for up to 80 min did not decrease the amounts of soluble OM. This result suggested that the disappearance of OM antigenicity in the baked bread took place in the fermentation process or in the baking, possibly by some interaction between OM and the wheat components. Consequently, the effect of fermentation on the disappearance of OM antigenicity was examined.

$\mathrm{OM}$ in the soluble fractions obtained from dough, with and without fermentation, was analyzed for its binding to anti-

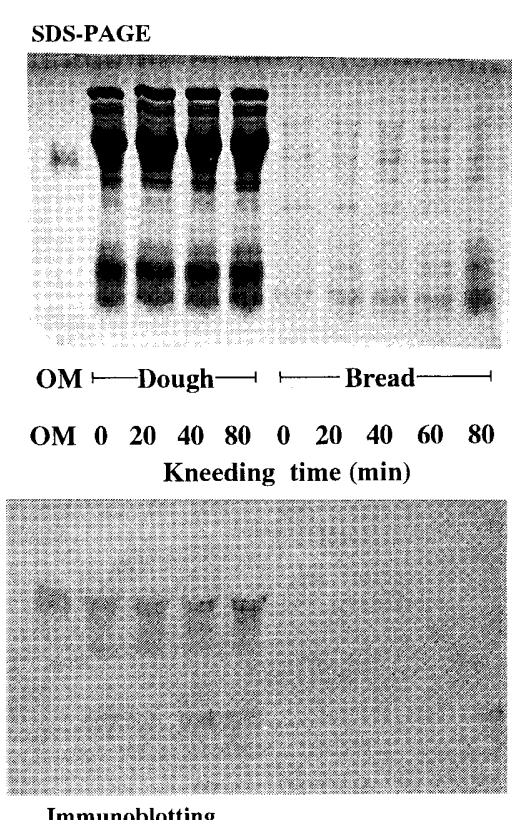

Fig. 1. SDS-PAGE and immunoblotting analysis for the antibody binding to ovomucoid in PBS-soluble proteins of dough and bread. The PBS-soluble proteins were obtained from dough and bread, and proteins (upper) and ovomucoid (down) were detected with CBB and rabbit anti-ovomucoid antibody, respectively. The total proteins extracted from $3.5 \mathrm{mg}$ of each of the dough and bread samples were loaded onto each lane of the PAGE.

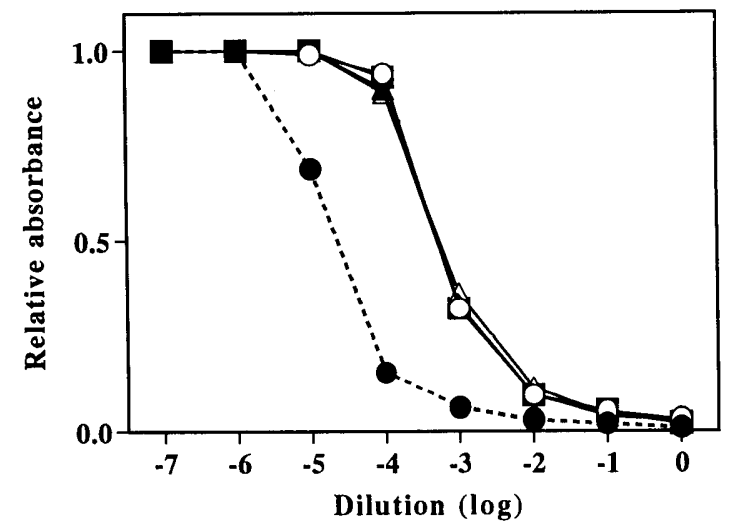

Fig. 2. ELISA competitive inhibition analysis for ovomucoid antigenic activity in dough kneaded for 0 to $80 \mathrm{~min}$. The soluble fractions obtained from the doughs kneaded for $0(\bigcirc), 20(\Delta), 40(\triangle)$ and $80(\square)$ min with the kneader and diluted serially. Diluted egg white samples (-) with weights of PBS equivalent to the dough samples were also analyzed as the standard. 
OM antibody by ELISA competitive inhibition (Fig. 2). The concentration of the soluble fraction from fermented dough required to attain $50 \%$ inhibition of the reaction between $\mathrm{OM}$ and anti OM serum was about 10 times greater than that of the standard egg white solution, and there was no difference between the OM antigenicity in the dough obtained before and after the fermentation. The standard egg white solution was prepared by the replacement of wheat flour and other ingredients with the same amount of PBS.

To estimate the effect of baking time, after baking at $180^{\circ} \mathrm{C}$ for 4 to $20 \mathrm{~min}$, OM antigenicities in the soluble fractions from the resulting breads were examined by competitive ELISA analysis (Fig. 3). The antigenicity of $\mathrm{OM}$ in the soluble fractions obtained from bread was determined by the amount required to attain 50\% inhibition of the reaction between OM and anti-OM antibody based on the standard egg white solution. The antigenicity of $\mathrm{OM}$ in the PBS fraction obtained from the bread baked at $180^{\circ} \mathrm{C}$ for $4 \mathrm{~min}$

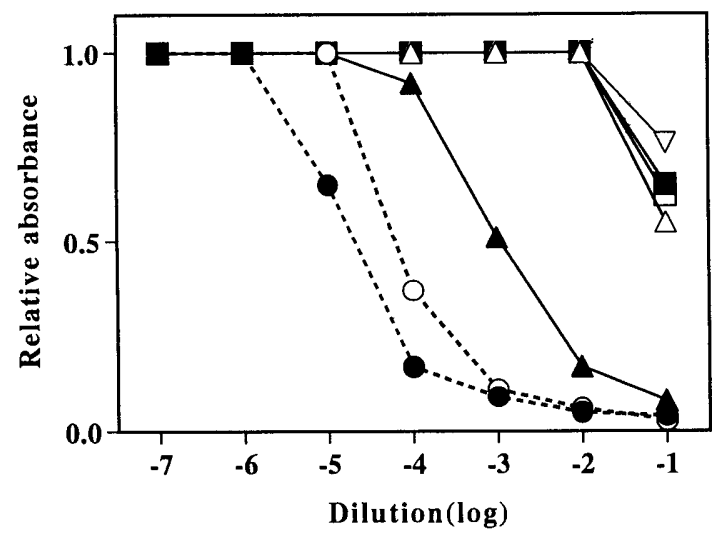

Fig. 3. ELISA competitive inhibition analysis for ovomucoid antigenic activity in baked bread. The soluble fractions were prepared from bread baked at $180^{\circ} \mathrm{C}$ for $4(\Delta), 8(\triangle), 10(\square), 12(\square), 16(\nabla)$ and $20(\nabla) \mathrm{min}$, and diluted serially. The numbers in the figure are baking time $(\mathrm{min})$ at $180^{\circ} \mathrm{C}$. $\bullet$ egg white samples diluted with weights of PBS equivalent to the dough samples were analyzed as standard. 0 ; the standard solution was heated at $180^{\circ} \mathrm{C}$ for $20 \mathrm{~min}$ and also analyzed. decreased to $1 / 60$ of that of the standard solution, though the $\mathrm{OM}$ antigenicity of the standard solution decreased to only $25 \%$ when baked at the same temperature for $20 \mathrm{~min}$. The OM antigenicities were not detected at all in PBS soluble fractions from breads baked at $180^{\circ} \mathrm{C}$ for $8 \mathrm{~min}$ or more.

The effect of baking time and temperature on the binding activities of OM to anti-OM antibody was also examined by ELISA competitive inhibition analysis (Fig. 4). The concentration of $\mathrm{OM}$ in the soluble fractions decreased with higher baking temperatures and longer baking times, and $\mathrm{OM}$ was hardly detectable after baking at $100^{\circ} \mathrm{C}$ for 20 min or more or at $120^{\circ} \mathrm{C}$ for $12 \mathrm{~min}$ or more. Also, OM antigenicity disappeared completely in breads baked at $150^{\circ} \mathrm{C}$ for $4 \mathrm{~min}$ or more.

The soluble protein samples extracted with $4 \%$ SDS and $4 \%$ SDS $+10 \%$ 2-ME from the dough and bread samples were analyzed by SDS-PAGE and immunoblotting using anti-OM serum (Fig. 5). A large amount of wheat proteins as well as egg white proteins including OM were extracted from the

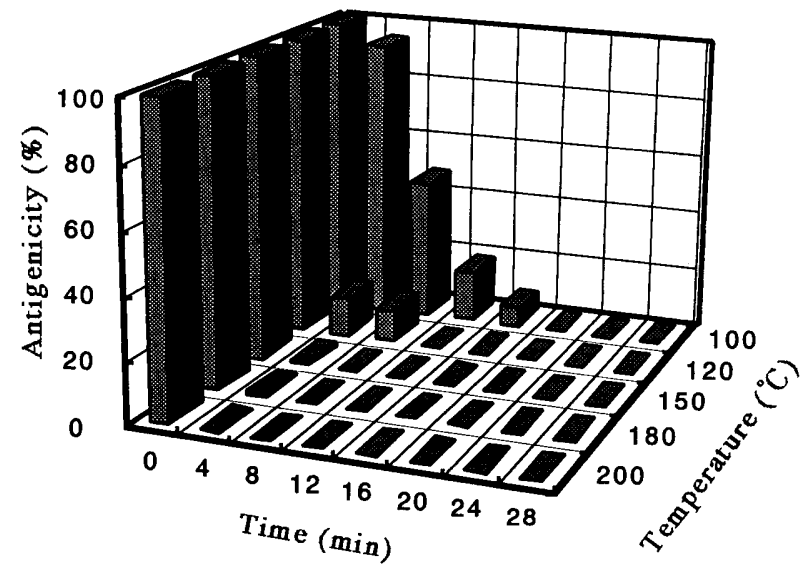

Fig. 4. Effect of baking time and temperature of dough on the antigenicity of OM analyzed by ELISA competitive inhibition. The soluble fractions were prepared from bread baked at $100^{\circ} \mathrm{C}$ to $200^{\circ} \mathrm{C}$ for 0 to $28 \mathrm{~min}$ and diluted serially.

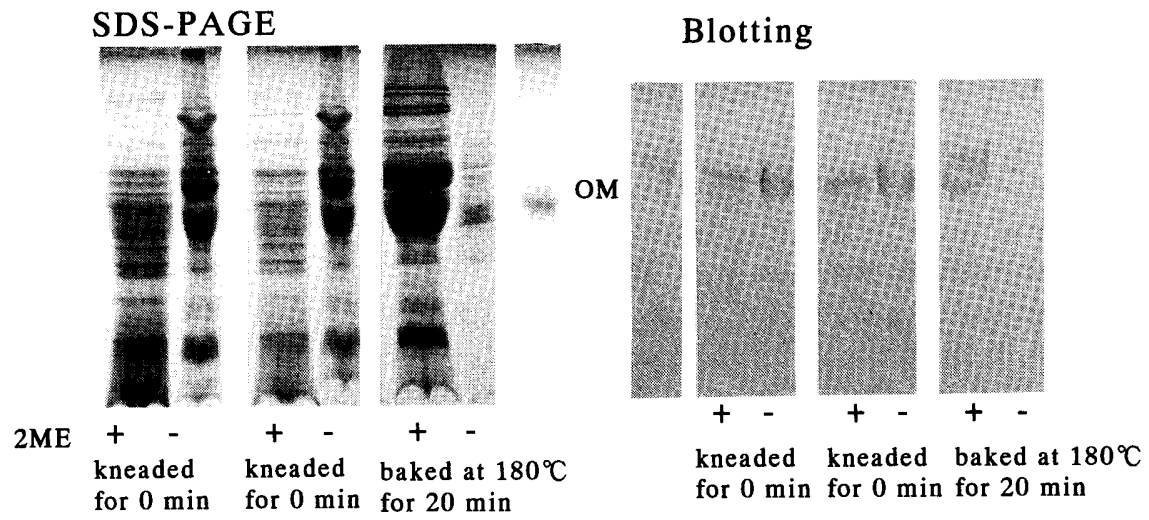

Fig. 5. SDS-PAGE and immunoblotting analyses for SDS-soluble proteins extracted from dough and bread samples in the presence and absence of 2-ME. Proteins were extracted from dough and bread samples with $4 \%$ SDS $+10 \%$ 2-mercaptoethanol (lane + ), or $4 \%$ SDS (lane - ) as described in Materials and Methods, and analyzed by SDS-PAGE and immunoblotting. The gel sheet and blotted membrane were stained with CBB (left panel) and the OM-specific antibody (right panel), respectively. The total proteins extracted from $0.7 \mathrm{mg}$ of each of the dough and bread samples were loaded onto each lane of the PAGE. 
dough with the SDS solution. On the other hand, only a few protein bands were detected in the SDS-extract of the baked bread, though many proteins were extracted from the bread with the SDS/2-ME solution. Furthermore, OM was detected with the specific antibody in the SDS/2-ME extracts. The same results were obtained when dithiothreitol was used instead of 2-ME. Thus, reducing agents in addition to a detergent is required for the solubilization of OM in baked bread samples.

OM prepared from boiled eggs still caused a skin reaction in allergic patients (Bleumink \& Young, 1969). The major soluble antigenic component in heated $\left(100^{\circ} \mathrm{C}\right.$ for $\left.20 \mathrm{~min}\right)$ and coagulated egg white was OM. Even extended heating $\left(100^{\circ} \mathrm{C}\right.$ for $\left.45 \mathrm{~min}\right)$ could not completely eliminate the OM immunoreactivity to human IgE antibody (Gu et al., 1986). On the other hand, heat treatment at $100^{\circ} \mathrm{C}$ in alkaline solution irreversibly caused ovomucoid to loss its antigenicity, and the reductive cleavage of intramolecular disulfide bonds in OM markedly reduced its immunochemical activity (Deutsch \& Morton, 1956; Matsuda et al., 1982; and Matsuda et al, 1985a). In this experiment, OM could not be extracted with PBS, even with the SDS solution, from the baked bread, though OM was clearly detected by immunoblotting or competitive ELISA after egg white was kneaded and fermented with wheat flour. The requirement of the reducing agents for the solubilization of OM in baked bread suggested that the baking with wheat flour induced a disulfide exchange reaction of OM leading to self-polymerization and/ or heterologous polymerization with other proteins through intermolecular disulfide bridges. The possible candidate for the interactive component is gluten, resulting in the decrease or loss of $\mathrm{OM}$ antigenicity. Because gluten has many free $\mathrm{SH}$ groups, the SH and SS interchange reactions between OM and gluten are possibly take place in the process of breadmaking. Studies on the interaction between $\mathrm{OM}$ and gluten are now in progress.

Acknowledgments This study was supported in part by a Grant-in Aid for Scientific Research from the Ministry of Education, Science, and Culture of Japan and the Iijima Memorial Foundation for the Promotion of Food Science and Technology.

\section{References}

Bleumink, E. and Young, E. (1969). Studies on the atopic allergen in hen's egg. I. Identification of the skin reactive fraction in egg white Int. Arch. Allergy, 35, 1-19.

Deutsch, H.F. and Morton, J.I. (1956). Immunochemical properties of heated ovomucoid. Arch. Biochem. Biophys., 64, 19-25.

Engvall, E and Perlmann, P. (1971). Enzyme-linked immunosorbent assay (ELISA). Quantitative assay of immunoglobulin G. Immunochemistry, 8, 871-874

Gu, J., Matsuda, T. and Nakamura, R. (1986). Antigenicity of ovomucoid remaining in boiled shell eggs. J. Food Sci., 51, 14481450 .

Hoffman, D.R. (1983). Immunochemical identification of the allergens in egg white. J. Allergy Clin. Immunol, 71, 481-486.

Laemmli, U.K. (1970). Cleavage of structural proteins during the assembly of the head of bacteriophage T4. Nature (London), 227, 680-685.

Langeland, T. (1982a). A clinical and immunological study on allergy to hen's egg white. II. Antigens hen's egg white studied by crossed immunoelectrophoresis (CIE). Allergy, Copenh., 37, 323-333.

Langeland, T. (1982b). A clinical and immunological study on allergy to hen's egg white. III. Allergens in hen's egg white studied by crossed radio-immunoelectrophoresis (CRIE). Allergy, Copenh., 37, $521-530$

Matsuda, T., Watanabe, K. and Sato, Y. (1981). Temperature-induced structural changes in chicken egg white ovomucoid. Agric. Biol. Chem., 45, 1609-1614.

Matsuda, T., Watanabe, K. and Nakamura, R. (1982). Immunochemical studies on thermal denaturation of ovomucoid. Biochim. Biophys. Acta, 707, 121-128.

Matsuda, T., Tsuruta, K., Nakabe, Y. and Nakamura, R. (1985a). Reduction of ovomucoid immunogenic activity on peptic fragment and heat denaturation. Agric. Biol. Chem., 49, 2237-2241.

Matsuda, T., Nakamura, R., Nakashima, I., Hasegawa, Y. and Shimokata, K. (1985b). Human IgE antibody to the carbohydratecontaining third domain of chicken ovomucoid. Biochem. Biophys. Res. Commun. 129, 505-510.

Matsuda, T. and Nakamura, R. (1993). Molecular structure and immunological properties of food allergens. Tends Food Sci. Technol., 4, 289-293.

Towbin, H., Steehelin, T. and Gordon, J. (1979). Electrophoretic transfer of proteins from polyacrylamide gels to nitrocellulose sheets: Procedure and some applications. Proc. Natl. Acad. Sci. USA, 76, 4350-4354. 